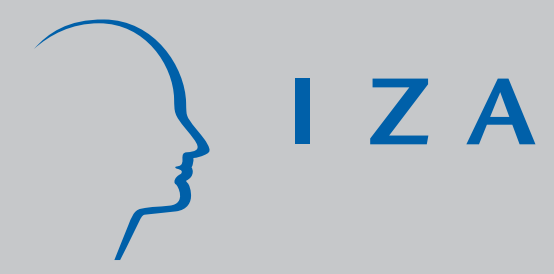

IZA DP No. 3715

The Benefits of Linking CGE and Microsimulation Models: Evidence from a Flat Tax Analysis

Andreas Peichl

September 2008 


\title{
The Benefits of Linking CGE and Microsimulation Models: Evidence from a Flat Tax Analysis
}

\author{
Andreas Peichl \\ University of Cologne \\ and IZA
}
Discussion Paper No. 3715
September 2008

IZA

P.O. Box 7240

53072 Bonn

Germany

Phone: +49-228-3894-0

Fax: +49-228-3894-180

E-mail: iza@iza.org

Any opinions expressed here are those of the author(s) and not those of IZA. Research published in this series may include views on policy, but the institute itself takes no institutional policy positions.

The Institute for the Study of Labor (IZA) in Bonn is a local and virtual international research center and a place of communication between science, politics and business. IZA is an independent nonprofit organization supported by Deutsche Post World Net. The center is associated with the University of Bonn and offers a stimulating research environment through its international network, workshops and conferences, data service, project support, research visits and doctoral program. IZA engages in (i) original and internationally competitive research in all fields of labor economics, (ii) development of policy concepts, and (iii) dissemination of research results and concepts to the interested public.

IZA Discussion Papers often represent preliminary work and are circulated to encourage discussion. Citation of such a paper should account for its provisional character. A revised version may be available directly from the author. 
IZA Discussion Paper No. 3715

September 2008

\section{ABSTRACT \\ The Benefits of Linking CGE and Microsimulation Models: Evidence from a Flat Tax Analysis*}

Mircrosimulation models (MSM) and Computable General Equilibrium models (CGE) have both been widely used in policy analysis. The combination of these two model types allows the utilisation of the advantages of both types. The aim of this paper is to describe the stateof-the-art in simulation and to demonstrate the benefits of linking both model types modelling flat tax reform proposals for Germany. Taking the general equilibrium effects into account has important implications for the evaluation of a tax reform. The analysis shows that a personal income flat tax can indeed overcome the fundamental equity efficiency trade-off in the longrun while simultaneously increasing the tax revenue. However, this result does not hold for a flat tax combining a personal income flat tax with a corporate cash flow flat tax, even when allowing for an ex-post loss in revenue.

JEL Classification: D58, H2, J22

Keywords: microsimulation, CGE, linked micro macro models, flat tax

Corresponding author:

Andreas Peichl

IZA

P.O. Box 7240

53072 Bonn

Germany

E-mail: peichl@iza.org

I would like to thank Christian Bergs, Markus Clauss, Clemens Fuest, Nicolas Hérault, Thilo Schaefer, seminar participants in Cologne and Leuven and participants of the EcoMod conference in Berlin for their helpful contributions. The usual disclaimer applies. 


\section{Introduction}

The introduction of a flat tax system is widely seen as a reform which may boost efficiency, employment and growth through simplification and higher incentives. However, inequality is expected to increase as a consequence of a flat tax reform. In the discussion of the flat tax "a notable and troubling feature [...] is that it has been marked more by rhetoric and assertion than by analysis and evidence". 1 Given that flat taxes have not yet been implemented in Western European countries, the effects of flat tax reforms in these countries can only be studied on the basis of simulation models. The method of simulation analysis aims at analysing and quantifying the economic effects of different policies based on the given institutional background to compare and evaluate different reform proposals with respect to equity and efficiency effects.

For the analysis of fiscal reforms, microsimulation (MSM) and computable general equilibrium (CGE) models have been widely used in the literature. CGE models consider various interdependencies and facilitate simulating behavioural responses and adjustments on several markets. In contrast, microsimulation models consider only the household side of the economy, which allows for more heterogeneity and a much more detailed mapping of the complex tax benefit system. Combining these two model types enables the utilisation of the complementary advantages. The aim of this paper is twofold. First, possibilities of linking microsimulation and CGE models are shown. Then the benefits of linking both model types are illustrated using a flat tax example for Germany.

The most popular flat rate tax proposal is the "Flat Tax" of Hall and Rabushka (1985) (HR), which combines a cash flow taxation on corporate incomes with the same single marginal tax rate on labour income. This proposal, however, has not been implemented in its pure form in any country yet. Previous reforms considered a flat rate personal income tax as an indirect progressive tax schedule with a basic tax allowance and a uniform marginal tax rate. In the literature, there are several simulation studies on efficiency and equity aspects of such (revenue neutral) flat income tax reforms. One focus of these studies is the impact on employment and growth. $^{2}$ A second group of studies focuses on the distributional effects of flat tax reforms. ${ }^{3}$ In summary, the main result of this literature is that a flat tax can increase the efficiency in terms of employment and growth but will most likely lead to redistribution in favour of high income households. All previous studies support the existence of a trade-off between equity and efficiency, i.e. either inequality and employment both increase or decrease but it is not

\footnotetext{
${ }^{1}$ Keen et al. (2007), p. 3.

${ }^{2}$ See e.g. Browning and Browning (1985) for the U.S., Heer and Trede (2003) for Germany, Cajner et al. (2006) for Slovenia or Jacobs et al. (2007) for the Netherlands.

${ }^{3}$ See e.g. Caminada and Goudswaard (2001) for the Netherlands, Aaberge et al. (2000) for Italy, Norway and Sweden, Decoster and Orsini (2007) for Belgium, González-Torrabadella and Pijoan-Mas (2006) for Spain, Fuest et al. (2007b) for Germany and Paulus and Peichl (2008) for a cross country study of 10 EU countries.
} 
possible to decrease inequality while increasing employment. However, a HR-type flat tax may lead to further efficiency gains due to more investment and labour demand as it is also likely to reduce tax distortions in the corporate sector. These outcomes, however, can only be analysed taking the general equilibrium effects into account.

The introduction of a HR-type flat tax reform has been analysed before, especially for the U.S. using CGE models. Browning and Browning (1985) estimate an increase in labour supply by $5 \%$. Stokey and Rebelo (1995) compare and summarise different studies for the U.S. and conclude that a flat tax reform would have little effect on the growth rate. Gale et al. (1996) analyse the effects of introducing a HR flat tax in the U.S.. They conclude that high income households profit most while households with low incomes suffer from a flat tax reform. Ho and Stiroh (1998) and Dunbar and Pogue (1998) show that high income households gain whereas especially middle income households are burdened by a flat tax reform. Ventura (1999) finds an increase in capital accumulation and a redistribution in working hours and income in favour of the top of the distribution. Altig et al. (2001) find that output, labour supply and wages increase and that the lowest income households lose through a flat tax. Cassou and Lansing (2004) find that a flat tax reduces growth in the short run if revenue-neutrality is maintained, but increases capital accumulation and therefore growth in the long run. Díaz Giménez and Pijoan-Mas (2006) analyse two different flat tax proposals for the U.S. and find that the reform with the lower (higher) marginal rate increases (decreases) output and inequality, but decreases (increases) aggregate welfare. However, in both scenarios the poor obtain significant welfare gains. Nielsen et al. (1999) find significant efficiency gains but negative distributional effects for a flat tax in Denmark. However, none of these studies uses a linked MSM-CGE model.

In this paper, we analyse a cash flow flat tax reform of the German corporate and personal income tax system according to the proposal by Mitschke (2004), which is closely related to the Hall-Rabushka idea. Our focus lies on the effects on tax revenue, income distribution, employment and economic growth. Our analysis is based on a simulation model for the German tax and transfer system (FiFoSiM) using income tax micro data and household survey data. To be able to simulate equity and efficiency effects within the same microeconometric framework, we use the linked MSM-CGE module of FiFoSiM. With its socio-economic and demographic structure, Germany can be seen as a typical Western European democracy. Therefore, the qualitative results of our analysis should be of interest to a wider range of countries. ${ }^{4}$

Our analysis yields the following results: Applying the linked model to a not revenue neutral flat tax proposal shows that taking the general equilibrium effects into account indeed increases the expected efficiency gains in the long-run. The overall employment effects are larger than the

\footnotetext{
${ }^{4}$ It has to be taken into account, though, that the structures of the tax benefit systems do vary considerably among the countries of Western Europe.
} 
labour supply reactions because of reduced costs of labour and capital resulting in increasing labour and investment demand. Therefore, a personal flat income tax can indeed overcome the fundamental equity-efficiency trade-off. However, combining this flat tax with a cash flow flat tax on business income still increases inequality due to the large gains at the top of the distribution. Therefore, due to their limited efficiency effects and their problematic short-term distributional impact, flat tax reforms are unlikely to spill over to the grown-up democracies of Western Europe.

The setup of this paper is as follows. Section 2 describes microsimulation models (MSM), computable general equilibrium models (CGE) and methods to link them. Section 3 briefly discusses potential problems of simulation studies. Section 4 describes the microsimulation and CGE model used for the application. In section 5, the flat tax reform proposal for Germany is decribed, which is analysed in section 6 . Section 7 concludes.

\section{Simulation models}

In this section, simulation models are introduced and described as a method for the ex-ante evaluation of the various consequences of fiscal reforms. Various proposals to reform the complex tax and benefit systems exist in every welfare state, and new proposals are being presented in policy debates each year. In the run-up of the implementation of a certain reform, in many cases the expected consequences remain an unsolved puzzle. Especially the behavioural responses of the (bounded) rational individuals are extremely difficult to estimate ex-ante. Knowing these responses, though, helps to evaluate and judge different reform proposals regarding their target achievement and cost efficiency. Estimating them, however, is not a trivial task. The complexity of existing welfare states requires the usage of simplified models for the evaluation of reform proposals. Theoretical models should be kept small and simple to be able to understand the general principles. They allow to point out a single argument in a simplified framework and to construct hypotheses which can be tested empirically. Empirical models allow for an econometric evaluation of a given reform and are especially useful whenever the magnitude, and thus not only the sign, of the effects are to be estimated. The quality of the empirical analysis crucially depends on the availability of high quality micro data. If the reform already has been implemented and data is available for the pre- and post-reform period, an ex-post analysis is possible using standard econometric procedures. On the other hand, if the reform has not been implemented, only simulation models can provide information for an ex-ante analysis of different reform proposals.

In general, simulation models are tools which are designed to answer "what if" questions about different policy reform options. The method of simulation analysis uses actual economic 
data to estimate how an economy might react to changes in external factors (e.g. policy parameters). Simulation models map the complex tax benefit system to analyse and quantify the effects of different policies based on the given institutional background. Other than in the natural sciences, it is seldom possible in economics to construct natural experiments for the analysis of a given treatment (policy). Policy simulations can be interpreted as quasiexperiments which allow the economist to ex-ante analyse a reform proposal controlling for behavioural responses of the micro units in the economy. Simulation models are frequently used by economists, policy-consultants and policy-makers to predict the impacts of changes in fiscal policies on individuals (gains and losses, income distribution), the government budget and key economic indicators (e.g. growth, employment, prices, consumption) to provide the political decision makers with well-founded decision guidance. This is done by setting up alternative scenarios by varying the rules of the tax benefit system and then simulating the impacts of these changes on individual and aggregated variables.

Several different types of simulation models can be used depending on the research question in mind. In the following, we focus on public economics models which can be used for the analysis of tax benefit reforms. The aim of this section is to describe the status-quo of the research in the field of simulation models by introducing and comparing the different types of models. The following subsections describe in more detail the standard procedures of computable general equilibrium models (CGE), microsimulation models (MSM) and linked micro macro models.

\subsection{Computable General Equilibrium Models (CGE)}

General equilibrium theory has provided important insights about mechanisms that determine the allocation of resources on mutually interdependent markets. Computable General Equilibrium $(\mathrm{CGE})^{5}$ models use this general equilibrium theory to empirically analyse and quantify this allocation of resources. CGE models are used instead of analytical general equilibrium models whenever the size and complexity make such analytical models mathematically intractable. Although CGE models are based on the microeconomic general equilibrium theory they usually use aggregated macro data for the analysis. The first CGE model was presented by Johansen (1960). With the development of fast computers and suitable software a large number of CGE models has been developed and applied to policy analysis since then.

CGE models use as realistic values as possible of exogenous variables (e.g. elasticities, tax rates) to numerically compute the values of the endogenous variables (e.g. prices, quantities)

\footnotetext{
${ }^{5}$ Sometimes this class of numerical economic models is also called Applied General Equilibrium (AGE) models. This subsection is based on Bergs and Peichl (2008). Further introductions to CGE models can be found in Kehoe and Prescott (1995), Fehr and Wiegard (1996) or Bergman (2005).
} 
with the aim of quantifying economic equilibria to compare the impact of policy measures on these equilibria. Applications of CGE models include analyses of tax reforms, changes in trade policy regimes, economic integration, agricultural policies and energy policies. The analysis focuses particularly on the long-run allocation of factors and goods, whereas shortterm distributional effects cannot be analysed in a sophisticated way using this type of models.

\subsubsection{Standard procedure}

A CGE model is usually a multi-sector model based on real world data of one or several national economies to model the interactions of individual households and firms on interdependent markets. However, in a typical CGE model there is only one or possibly a few representative agents, while the number of firms (production sectors) is generally larger. A CGE model consists of equations describing the variables and a database consistent with these equations. For all agents (households, firms, government) an optimising behaviour, i.e. utility and profit maximization on the part of households and firms, is assumed to model their behaviour on different markets. In general, standard models assume product and factor markets to be competitive and relative prices flexible enough to simultaneously clear all markets. However, it is possible to allow for non-market clearing (e.g. unemployment or inventories), imperfect competition (e.g. monopolistic competition $)^{6}$, heterogeneous agents, and taxes or externalities (e.g. pollution). CGE models are almost always focused on the real side of the economy and thus do not include financial assets. Consequently a typical CGE model endogenously determines relative product and factor prices, but cannot determine nominal prices. In particular CGE models are aimed at quantifying the impact of specific policies on the equilibrium allocation of resources and relative prices of goods and factors.

For the numerical computation of equilibria, it is essential to specify functional forms of production and utility functions as well as the values of the exogenous parameters of the model. The specification of these functions and parameters is of key importance for the model results. There are two general approaches. On the one hand, these parameters can be estimated using econometric methods based on time series or panel data, or, on the other hand, these values can be calibrated ${ }^{7}$ using a micro consistent dataset reflecting an economic equilibrium at a given point in time. Often both methods are combined and some parameters are estimated (or estimates are taken from the literature) and other parameters are calibrated to replicate the benchmark equilibrium given in the data. The construction of a micro consistent database can be rather time consuming if information from several sources has to be combined. In general, the skeletal structure is based on an input-output-table which is enhanced to a so called "Social

\footnotetext{
${ }^{6}$ See e.g. Harris (1984).

${ }^{7}$ See Mansur and Whalley (1984) and Lau (1984) for an extensive discussion of the calibration method.
} 
Accounting Matrix“ (SAM). ${ }^{8}$

CGE models allow quantifying the impacts of policy reforms. However, they - as all models do - obviously rest upon strong simplifying assumptions about optimising behaviour, competitive markets and flexible prices. Furthermore, the calibration method which is often used to define key model parameters is often seen to be rather arbitrary. In view of this, the validity and therefore also the usefulness for policy evaluation of the results is often seriously questioned. However, the usefulness of a CGE model depends on the aims and purposes it was designed for and what the alternatives are. If a general equilibrium model cannot be solved analytically, a numerical solution can help to identify general equilibrium effects of policy changes even if key parameters of the model are quite uncertain. The role of these parameters for the results can be explained using extensive sensitivity analyses. Furthermore, even if the precise magnitude of the effects remains uncertain, it still might be possible to identify if the effects are small or large or at least to compare and rank different scenarios based on these results.

\subsubsection{CGE categories}

Different categories of CGE models can be distinguished. First of all, it should be emphasised that the models within each category can differ in many ways (e.g. heterogeneity in terms of number of agents, sectors, factors or commodities, as well as the representation of the government or foreign trade with the rest of the world). Nevertheless, some common elements can be attributed to different categories. The most appropriate classification for most modelling approaches is to distinguish between static and dynamic models. In addition it is useful to distinguish between single-country (national) and multi-country (global) models. Generally, single-country models are much more detailed in terms of sectors and household types and are especially designed to analyse country-specific policy issues. Multi-country models are used for multi-lateral policies (e.g. trade agreements, emission trading schemes) and are usually less detailed in terms of intra country heterogeneity.

Comparative-static models are by far the most common class of CGE models. ${ }^{9}$ The economy is modelled at two given points in time only: the status quo benchmark and the future counterfactual equilibrium. The results of these models are the long-run differences (usually reported in percent changes) between the benchmark equilibrium and the future equilibrium to which the economy converges after a given exogenous shock. The transition path towards this new equilibrium is not explicitly modelled. This, however, allows for a more detailed specification of the single-period economy in terms of numbers of agents, sectors or commodities to be

\footnotetext{
${ }^{8}$ See Pyatt and Round (1985) and Kehoe (1998) on how to construct a SAM.

${ }^{9}$ See e.g. Shoven and Whalley (1984), Shoven and Whalley (1992) or Kehoe and Kehoe (1994) for an introduction.
} 
represented in the model.

Dynamic CGE models, by contrast, explicitly model this transition path. The equilibrium is computed for all future points in time (at discrete intervals) until the model horizon ends. These models are far more challenging to design, maintain and solve but allow a more realistic representation of the adjustment process of a policy change. However, the increasing complexity of dynamic models often reduces the heterogeneity of the agents and therefore, in general, smaller number of agents and sectors are represented in dynamic models. Dynamic models assume rational expectations of agents, i.e. they use all available information for the best guess of the future. This makes it necessary to simultaneously solve for all periods. Stochastic CGE models explicitly incorporate uncertainty about the future into the analysis. In contrast, recursive-dynamic CGE models assume that behaviour depends only on current and past states of the economy (assuming myopic expectations). ${ }^{10}$ These models can be solved sequentially (one period at a time). Dynamic models can be further distinguished according to the representation of the household side of the economy. CGE models based on the Ramsey (1928) growth model assume an infinitely living representative agent. In contrast, overlapping generations (OLG) models assume periodically overlapping generations. These models can be further distinguished into models with identical lifetime for all generations (see Auerbach et al. (1983) and Auerbach and Kotlikoff (1987)) or models with a stochastic time of death (see Blanchard (1985)).

\subsubsection{Applications}

There are many fields for applications of CGE models in economics. The short review in this section focuses on recent models for the analysis of tax reforms especially in Germany. ${ }^{11}$

Hutton and Ruocco (1999) use a static model to analyse different tax reforms in Germany, France, Italy and the UK especially with respect to their labour market performance. Sørensen (2002) also uses a static model for the analysis of the German tax reform of 2000.

Keuschnigg and Dietz (2003) use an OLG model to analyse the corporate tax reform in Switzerland. This model is adapted to Germany by Radulescu and Stimmelmayr (2004) who analyse the introduction of a dual income tax. Fehr and Wiegard (1998) use an AuerbachKotlikoff OLG model to analyse different income tax reform proposals.

Graafland et al. (2001) and Bovenberg (2003) use the recursive-dynamic model MIMIC to analyse the impact of tax reforms on the Dutch labour market. The German PACE-L model was constructed following the MIMIC approach. This model is used to analyse the labour market effects of hypothetical income tax (Boeters, Gürtzgen and Schnabel (2006)), VAT (Boeters,

\footnotetext{
${ }^{10}$ See Ballard et al. (1985).

${ }^{11}$ See e.g. Fehr and Wiegard (1996) for a review of additional models. An application for the US can for example be found in Altig et al. (2001).
} 
Böhringer, Büttner and Kraus (2006)) or welfare (Böhringer et al. (2005)) reforms.

\subsection{Microsimulation Models}

Microsimulation models (MSM) are quantitative models of the tax benefit system and have been introduced into social sciences and economics by Orcutt (1957) and Orcutt et al. (1961). ${ }^{12}$

\subsubsection{Standard procedure}

Microsimulation models are partial equilibrium models focusing on one side (e.g. the household side) of markets and do not consider the broader economic environment in which the micro units are acting. Tax benefit models usually only simulate first round effects where the behavioural response of the agents (to the change imposed on the system) is not captured. These tax benefit models can be combined with a labour supply model allowing the simulation of (partial) second round effects in terms of behavioural responses on the labour market.

In the centre of this microanalytic approach is the behaviour of individual agents to which the observed social and economic processes can be attributed. MSM are based on micro data which offer a great flexibility especially regarding a detailed mapping of the complex tax benefit system. These data samples allow the modelling of structural characteristics of micro units (persons, households, firms) within a particular tax benefit system. This allows MSM to reflect the considerable heterogeneity within the population by taking into account the characteristics and circumstances of each individual. MSM can be used to analyse the status quo of tax benefit rules by providing detailed data on single policy variables. Furthermore, these factuals are then used as a benchmark (baseline) to evaluate the impact of a reform scenario. Such a counterfactual can be a single policy or various interacting and interdependent policies within the complex tax benefit system as well as fundamental reform proposals of the whole system. To analyse a reform scenario, the socioeconomic system is modelled and applied to the sample micro units, which in turn are weighted with population weights to extrapolate results for the whole population. Therefore, the results of MSM can be analysed either at the individual level or at different levels of aggregation. Despite these advantages there are some limitations. Every empirical analysis relies on high quality data of all key variables. If such data is not available, simplifying assumptions are necessary which lead to biased estimations. If, e.g., key information necessary for some (minor) tax rules is not available, it is not possible to include these rules into the mapping of the tax benefit system.

\footnotetext{
${ }^{12}$ This subsection is based on Peichl (2005). See e.g. Gupta and Kapur (2000), Harding (1996) or Bourguignon and Spadaro (2006) for further MSM surveys.
} 


\subsubsection{MSM categories}

Microsimulation models can be differentiated according to the time dimension into static and dynamic models and according to the modelling of behavioural responses into behavioural and non-behavioural models.

\subsubsection{Static vs. dynamic MSM}

Static MSM use cross-sectional data at a given point in time. Often this data has to be aged to the year of analysis which might be further in the future using the static ageing technique, i.e. reweighting of individual records based on macroeconomic indicators. ${ }^{13}$ Static models mimic the tax law by applying the (current or an alternative set of) tax benefit rules to individual units. These models are essential tax benefit calculators for all individuals and therefore allow to model the tax benefit rules for every point of the income distribution. This allows the user to simulate the instantaneous first-round effects (in terms of the fiscal and distributional effects, i.e. the gains and losses in different variables at the individual or aggregated level) of policy changes. They allow for a comparative-static analysis of the pre- and post-reform state of the economy without looking at the adjustment process.

Dynamic MSM try to endogenously explain this process of adaptation through the incorporation of dynamic ageing of individual records over time based on the probabilities of the happening of different real life events (e.g. marriage, divorce, birth of a child). The relevant life processes are simulated and the individual characteristics are recalculated at each period in time which allows moving the micro units forward through time. On the one hand, dynamic MSM allows the modelling of demographic changes over time, but on the other hand, dynamic models have a higher demand regarding the modelling, the data requirements and the computational resources than static models. Therefore, often static models which are easier to build and maintain are used in combination with a behavioural model for the analysis of the short-term effects of policy reforms.

\subsubsection{Behavioural responses}

Behavioural responses can be simulated with both static and dynamic models. Sometimes behavioural models are labelled dynamic. Although dynamic models often include behavioural responses, they do not necessarily have to include them.

Non-behavioural models do not allow the individuals to change their behaviour as a consequence of a given policy reform. These models are often used to estimate the immediate fiscal and distributional effects. This is done by generating income profiles for various groups

\footnotetext{
${ }^{13}$ See Gupta and Kapur (2000) for a review of the ageing techniques.
} 
of individuals to highlight discontinuities in the tax benefit rules which in turn can be modified by policy-makers.

Behavioural models simulate some kind of behavioural response to a policy change. These responses can include the supply and demand of factors and goods. The most common applications are models of labour supply. Labour supply models allow the modelling of both the extensive (participation) and the intensive (hours worked) labour supply decision. The labour supply model can be either integrated into the microsimulation model or it can be linked to a MSM as an external module. There are several possibilities of how to model the labour supply of a tax unit (e.g. individual vs. household labour supply, discrete vs. continuous working hours, selection of utility functions). Recent surveys of the empirical labour market literature and different kinds of labour supply models are for example provided by Heckman (1993), Blundell and MaCurdy (1999) or Creedy et al. (2002).

\subsubsection{Applications}

Various microsimulation models exist worldwide. The review in this subsection focuses on German models which are used for the analysis of reforms of the tax benefit system. ${ }^{14}$

Wagenhals (2001) uses GMOD to simulate the fiscal and distributional effects of the income tax reform act of 2000. Haan and Steiner (2005) use STSM to estimate the fiscal, distributional and labour supply effects of the income tax reform act of 2000. Steiner and Wrohlich (2004) analyse the labour supply effects of the German system of family taxation. Merz and Zwick (2002) and Merz et al. (2002) analyse the income tax reform act of 2000 with MICSIM especially with respect to the upper end of the income distribution.

Immervoll et al. (2007) use the European model EUROMOD to analyse different reform scenarios in the EU-15 countries and Paulus and Peichl (2008) analyse and compare the distributional and incentive effects of different flat tax reforms in these countries.

\subsection{Linked Micro-Macro Models}

\subsubsection{Standard procedure}

On the one hand, CGE models provide an economy wide perspective of a given shock after the economy has fully equilibrated. The need to specify and calibrate functional forms and parameters for all agents on all markets reduces the number of agents to be modelled dramatically. Therefore, in general, few representative agents are used which reduces flexibility and the possibilities of a detailed modelling of the tax-benefit system. In consequence, these models give no insight into how aggregate changes in the economy and the new equilibrium

\footnotetext{
${ }^{14}$ See e.g. Wagenhals (2004) or O'Hare and Gupta (2000) for further surveys.
} 
solution affect individuals. On the other hand, MSM are based on micro data which offers great flexibility specifically regarding the mapping of the complex tax benefit system. These models are partial equilibrium models focusing on one side (e.g. the household side) of markets and do not consider the broader economic environment in which the micro units are acting.

During the last years, a tendency of linking micro and macro models has emerged in computational economics to utilise the complementary advantages of MSM and CGE models. ${ }^{15} \mathrm{~A}$ linked model can provide a more powerful tool for policy analysis than using results from two stand-alone MSM and CGE models. ${ }^{16}$ Outputs from the macro model can be used to align the predictions of the micro model and to enable general equilibrium feedbacks and interactions among variables in the micro model. Outputs from the micro model can be used to calibrate the macro model and provide a microeconomic basis for aggregate behaviour. Hence, the key advantage of a linked micro macro model is the feedback which is used to resolve the model corresponding to a revised set of parameters. However, achieving these feedback effects through linking MSM and CGE models is not a trivial task.

The idea of linking micro- and macroeconomic simulation models is almost as old as the stand-alone models themselves. ${ }^{17}$ Orcutt (1967) suggests to link models operating at different levels of aggregation through intermediate variables. Nevertheless, the number of researchers developing linked micro macro models is still very small worldwide (see Davies (2004)). Nonetheless, recent advances in computational and econometric methods are leading to a growing interest in combining these modelling techniques. The yet recent development in this area can be clearly attributed to the progress in computer and information technology which makes these large-scale models feasible to solve.

There are two general possibilities for linking the models. On the one hand, one can completely integrate both models into a joint model ${ }^{18}$ or on the other hand, one could combine two separated models via interfaces (layered approach). ${ }^{19}$ The first approach requires the complete micro model to be included in the CGE model which demands high standards for the database and the construction of the integrated model. This often results in various simplifying assumptions.

The layered approach can be differentiated into "top-down" (see Figure 1, left-hand side), "bottom-up" (see Figure 1, right-hand side) or "top-down bottom-up" (see Figure 2) ap-

\footnotetext{
${ }^{15}$ Cf. Davies (2004) for an overview. Most of these models deal with trade liberalization in developing countries.

${ }^{16} \mathrm{Cf}$. Anderson (1990).

${ }^{17}$ See Orcutt (1967) or Conrad (1991) for Germany.

${ }^{18}$ Cf. Cogneau and Robilliard (2000) or Cororaton et al. (2005). See also Arntz, Boeters and Gürtzgen (2006) for description of how to integrate a discrete choice labour supply into a CGE model.

${ }^{19}$ Cf. Bourguignon et al. (2003).
} 

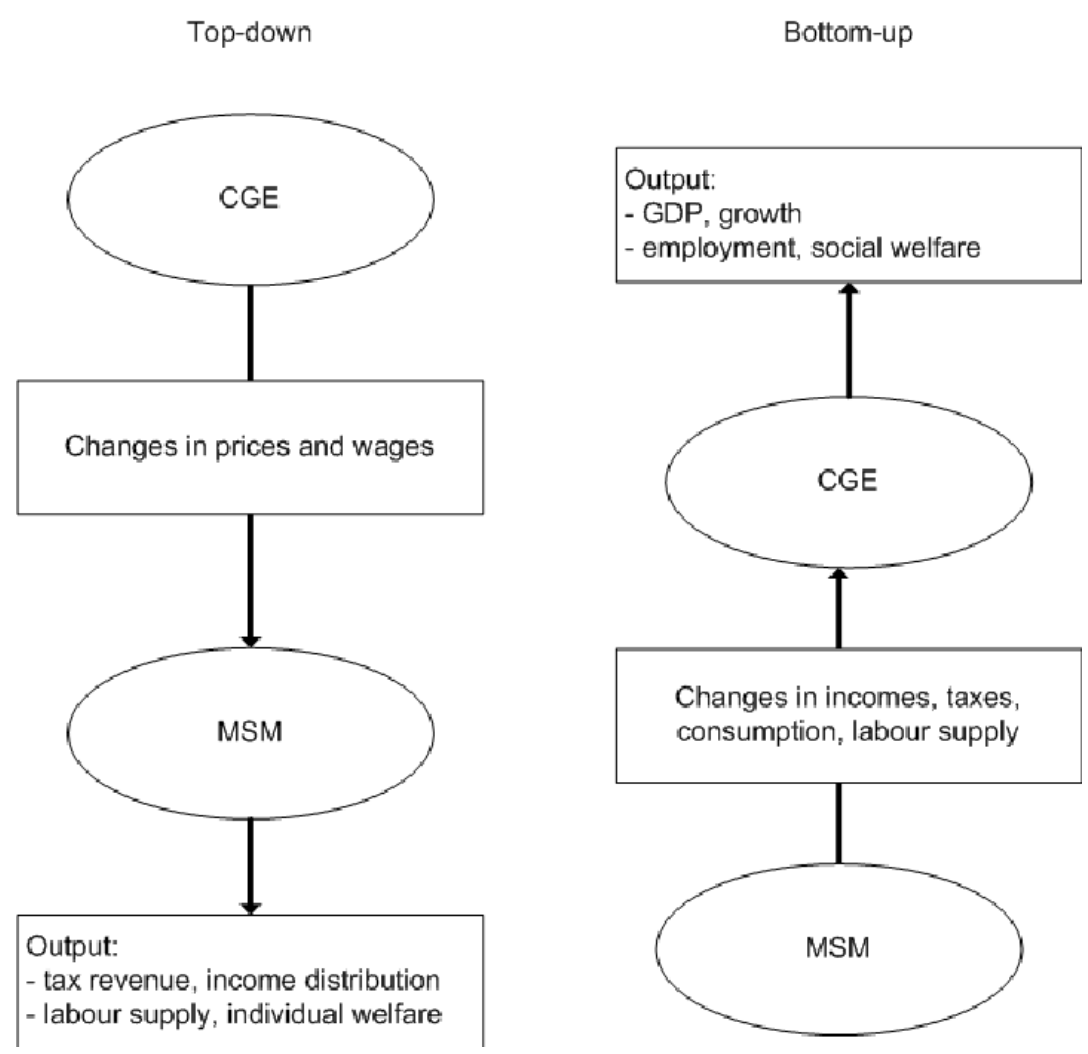

Figure 1: Top-down and bottom-up

proaches. ${ }^{20}$ The top-down approach computes the macroeconomic variables (price level, growth rates) in a CGE model as input for the micro model which is adjusted to match an exogenous macro aggregate. The bottom-up approach works the other way around and information from the micro model (elasticities, tax rates) is used in the macro model (e.g. for calibration of the representative agents). Both approaches suffer from the drawback that not all feedback is used. The top-down bottom-up approach combines both methods to a recursive approach. In an iterative process one model is solved, information is sent to the other model, which is solved and gives feedback to the first model. This iterative process continues until the two models converge. Böhringer and Rutherford (2006) describe an algorithm for the sequential calibration of a CGE model to use the top-down bottom-up approach with micro models with large numbers of households.

\footnotetext{
${ }^{20}$ Cf. Savard (2003) or Böhringer and Rutherford (2006).
} 


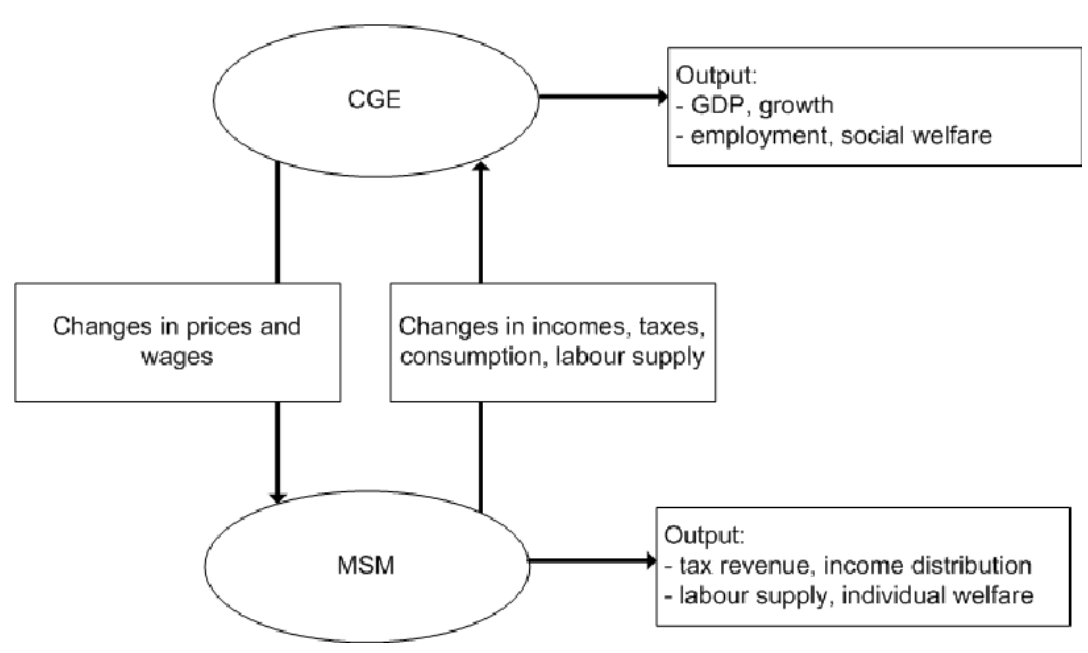

Figure 2: Top-down bottom-up

\subsubsection{Applications}

So far, the application of linked micro macro models to analyse tax reforms is rather limited..$^{21}$ Boeters et al. (2005) use the bottom-up approach to calibrate the three representative households of a CGE model to analyse different hypothetical reform proposals of the social assistance benefit system in Germany. ${ }^{22}$ A similar approach is chosen by Fuest et al. (2005a) to evaluate a tax reform proposal for Germany with respect to fiscal, employment and growth effects. Arntz, Boeters, Gürtzgen and Schubert (2006) use the recursive top-down bottom-up approach to analyse reform proposals designed to encourage labour supply at the lower end of the wage distribution in Germany. However, various simplifying assumptions regarding the aggregation and disaggregation of information on labour supply responses that is passed between the models have to be made.

Aaberge et al. (2007) use an integrated micro macro model of Norway to analyse the impact of population ageing on fiscal sustainability with endogenous labour supply. Although their model is integrated, they use an iterative approach. Labour supply responses are computed using the MSM model and are then used in the CGE model to estimate changes in wage rates.

Rutherford et al. (2005) link a CGE model to the Russian Household Budget Survey (representing 55,000 households) in order to analyse the distributional effects of Russia's WTO accession. They use the information of the micro model to calibrate the representative agent of the CGE model and iterate both models until they converge in terms of price changes and

\footnotetext{
${ }^{21}$ There are, however, more applications to trade reforms (see e.g. Davies (2004) for a survey). More recent applications include Hérault (2007), who uses the top-down approach to analyse the effect of trade liberalisation on poverty in South Africa.

${ }^{22}$ The same model and approach is also used by Boeters, Gürtzgen and Schnabel (2006).
} 
aggregate demand equalling aggregate supply.

\subsection{Summarising comparison of model types}

The method of simulation analysis can be seen as an economic quasi-experiment for the ex-ante evaluation of policy reforms to analyse and compare the impacts of different reform scenarios before they are implemented in real life. Different types of simulation models evolved over time. The three most common and appropriate models for the analysis of fiscal reforms, microsimulation models (MSM), computable general equilibrium models (CGE) and linked micro macro models have been described in this section. The main research questions for these categories are presented in Table 1.

\begin{tabular}{l|lll} 
& CGE & MSM & Micro-Macro \\
\hline \hline Framework & total & partial & total \\
Data & macro & micro & both \\
Research questions: & & & \\
- Growth & $\checkmark$ & & $\checkmark$ \\
- Allocation / Efficiency & $\checkmark$ & $(\checkmark)$ & $\checkmark$ \\
- Labour supply & $(\checkmark)$ & $\checkmark$ & $\checkmark$ \\
- Labour demand & $\checkmark$ & & $\checkmark$ \\
- Revenue & & $\checkmark$ & $\checkmark$ \\
- Distribution & & $\checkmark$ & $\checkmark$
\end{tabular}

Table 1: Comparison of model types

CGE models excel through their outstanding theoretical foundation and the consideration of various interdependencies. They allow estimating various behavioural responses and adjustments on several markets, e.g. modelling labour supply and demand on the labour market. In contrast, microsimulation models take only the labour supply side into account. Nevertheless, these models allow for a much more detailed mapping of the complex rules of the tax benefit system and account for a much greater heterogeneity than CGE models could ever do because of the aggregated data they are based on. Furthermore, the need to specify and calibrate functional forms and key parameters gives rise to various critiques against CGE models because of limited econometric foundations of the calibration technique in general. During the last years, a tendency of linking micro and macro models has emerged to utilise the complementary advantages of MSM and CGE models.

So far, the linked micro macro models which have been used for the analysis of tax benefit reforms do not sufficiently use all the possibilities stand-alone MSM and CGE models offer. The further development of computational power and more powerful algorithms (see e.g. Rausch and Rutherford (2007)) should allow for a complete integration of both types of models. This in 
turn will then enable to analyse the complex interdependence of various policy measures with respect to fiscal, distributional, employment and growth effects within the same econometric framework. Further development on the microsimulation modelling of the corporate sector is also desirable. This, of course, crucially depends on the availability of corporate micro data. Such a corporate MSM could then be linked with a household MSM and integrated into a CGE model which would then be based on micro data for both sides of the economy.

\section{Potential problems}

When conducting a simulation analysis or interpreting its results one should be aware of potential errors or biases. According to Betson (1990) "sampling errors", "imputation errors", "ageing errors", "individual response errors" and "environmental errors" can be distinguished in general. Sampling errors can always occur when subsamples from the whole population are used in an empirical analysis which can increase or decrease the variation in the data. Thus, estimates from the simulation model might differ from estimation based on the whole population. If the sample was not drawn randomly, the assumptions of statistical procedures might be violated and special corrections have to be used in the analysis. Furthermore, there might be also "non-sampling errors" in the dataset, resulting e.g. from non-response and reporting or data processing mistakes. The weighting of the individual records with population weights to estimate aggregated values for the whole population can reduce these errors, as the weighting factors are chosen to ensure that the sample estimates conform to macroeconomic indicators of the whole population. However, when these population factors are modified, e.g. using static ageing techniques of reweighting, this can give rise to ageing errors if the modification itself is biased. Imputation errors arise when data from different sources are used for the imputation of missing values or variables. As a consequence, distributional assumptions might be violated leading to biased estimations. But not only the data is error-prone but also the modelling of the benchmark or the counterfactual scenario itself gives rise to potential mistakes. Individual response errors can arise from simplifying and/or behavioural assumptions in the model. Simplifying assumptions are always subject to errors, but have to be used to overcome data limitations or to make the model operational. Behavioural assumptions are necessary for the estimation of behavioural responses. To do so, functional forms and co-variables of the econometric model have to be specified based on beliefs of the underlying behaviour of the individuals. Incomplete or imperfect beliefs can lead to misspecifications and biased results. Environmental errors can e.g. arise from the negligence of the broader economic environment or individual reactions to policy changes.

When conducting a micro-macro linkage, several specific potential problems arise. To be 
able to successfully link MSM and CGE models there have to be some common variables through which the two models can exchange information. Usually, it is necessary to aggregate or disaggregate these variables to be comparable with the variables in the other model. Of course, the less variables have to be (dis)aggregated the more of the underlying heterogeneity in the data will be retained. Furthermore, it has to be checked if the same variable in both models represents the same population (e.g. household consumption in the micro model vs. aggregated total consumption including government in the macro model). Functional forms (e.g. the preference functions in the labour supply model and the aggregated utility in the CGE model) have to be specified in a consistent way. ${ }^{23}$ In addition, it has to be checked if one run of each model represents the same time horizon. Usually, a MSM computes short-term effects, whereas a CGE models aims at the long-run equilibrium. ${ }^{24}$ Therefore, the information exchange between both models has to take into account these temporal differences. If, for example, a given labour supply shock from the MSM model has not fully equilibrated within the CGE model and information is passed back and forth again, a second labour supply shock might overlap the first one and either foil or fortify the first shock.

When building and using a simulation model, a researcher should be aware of these potential errors and should try to avoid them if possible or at least to document the possible biases in the analysis. Extensive sensitivity analyses should be conducted when building a model or simulating a new scenario. When interpreting the results of a simulation study, one has to be aware of these potential errors and has to take a closer look at the underlying data, methods and assumptions. Furthermore, estimations from simulation models should not be used as an exact forecast of a single number but to compare and rank different scenarios according to various dimensions. Despite all these potential errors, simulation models nevertheless provide a powerful tool for the ex-ante evaluation of fiscal policy reform proposals.

\section{Database and model}

Our analysis is based on a behavioural simulation model for the German tax and transfer system (FiFoSiM) using income tax and household survey microdata. ${ }^{25}$ The approach of FiFoSiM is

\footnotetext{
${ }^{23}$ Verboven (1996) shows that a nested logit specification of the individual direct utility function (which is usually used in labour supply models) can be aggregated to a global CES utility function (which is usually used in CGE models).

${ }^{24}$ This is, of course, not always the case. The temporal horizon of CGE models depends on the closure conditions. Particularly the closures for the capital market can be designed such that the CGE model can be used for short or medium term analyses with a fixed stock of capital not mobile across sectors.

${ }^{25}$ This section is based on the English documentation of FiFoSiM (see Peichl and Schaefer (2006)), which is a short version of the detailed German description (see Fuest et al. (2005b)). Due to a lack of space, we are not able to report the equations underlying the formal structure of the model in this paper. They can be, however, found in the model documentation. See also www.cpe-cologne.de for further information.
} 
innovative insofar as it creates a dual database using two micro data sets for Germany: FAST01 and GSOEP. ${ }^{26}$ FAST01 is a microdataset from the German federal income tax statistics 2001 containing the relevant income tax data of nearly 3 million households in Germany. Our second data source, the German Socio-Economic Panel (GSOEP), is a representative panel study of private households in Germany. The simultaneous use of both databases allows for the imputation of missing values or variables in the other dataset using techniques of statistical matching.

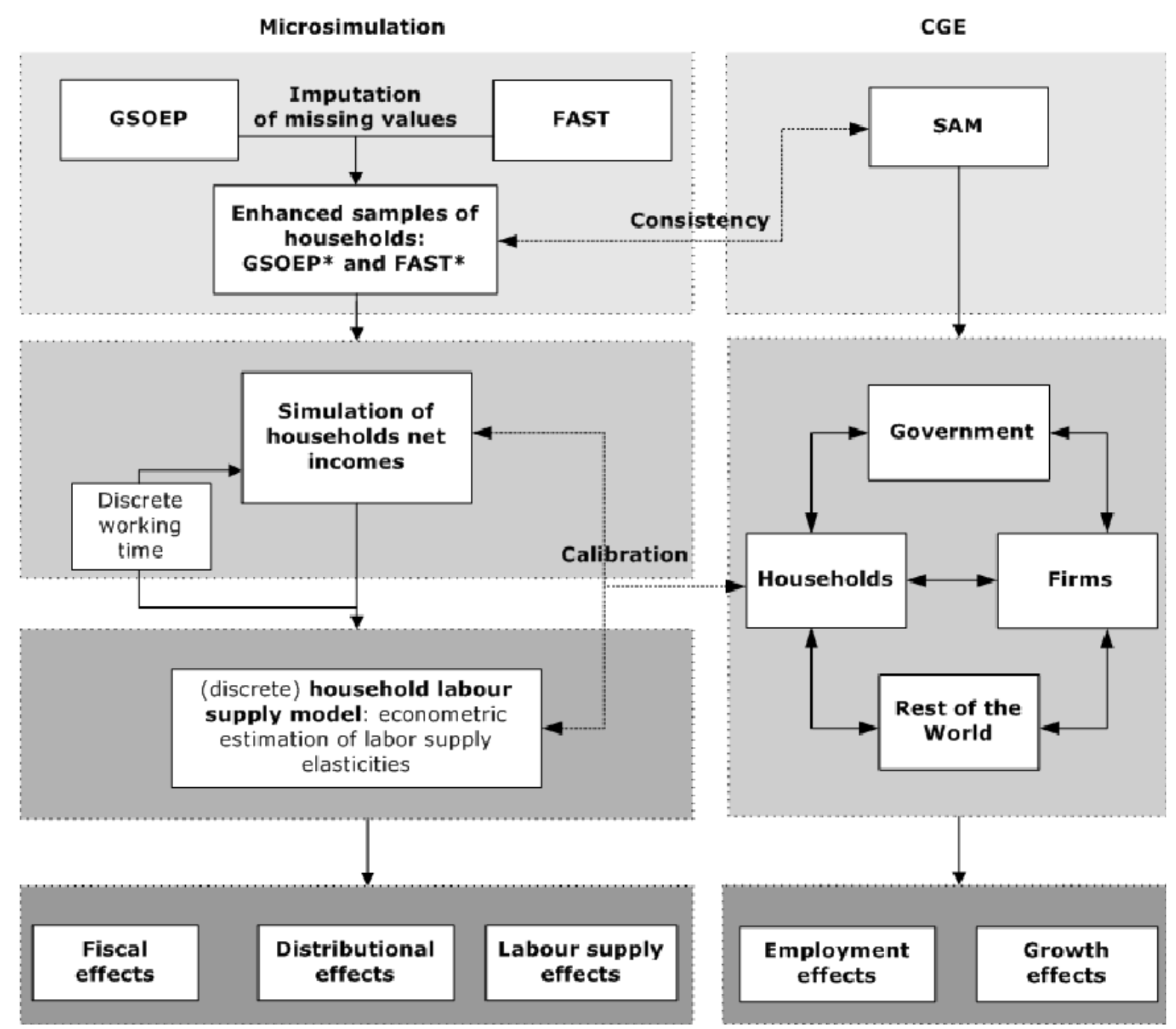

Figure 3: Basic setup FiFoSiM

Figure 3 shows the basic setup of FiFoSiM. The layout of the tax benefit module follows

\footnotetext{
${ }^{26}$ In the last years several tax benefit microsimulation models for Germany have been developed (see for example Peichl (2005) or Wagenhals (2004)). Most of these models use either GSOEP or FAST data. FiFoSiM is so far the first model to combine these two databases.
} 
several steps: First, the database is updated using the static ageing technique which allows controlling for changes in global structural variables (through reweighting of the sample) and a differentiated adjustment for different income components of the households (through uprating of various income components). Second, we simulate the tax and benefit system in 2008 using the uprated data. This allows us to compute the disposable incomes for each person and household taking into account the detailed rules of the complex tax benefit system. The basic steps for the calculation of the personal income tax under German tax law are as follows. The income of a taxpayer from different sources is allocated to the seven forms of income defined in the German income tax law. For each type of income, the tax law allows for certain specific income related expenses. Then, general deductions like contributions to pension plans or charitable donations are taken into account and subtracted from the sum of incomes, which gives taxable income as a result. Finally, the income tax is calculated by applying the tax rate schedule to taxable income. To derive the disposable income $Y$ from gross income $G$, received benefits (like unemployment benefit, social assistance, child benefits, etc.) are added and taxes $T$ and social insurance contributions $S$ are subtracted:

$$
Y=G+B-T-S
$$

Third, the individual results are multiplied by individual sample weights to extrapolate the fiscal effects of the reform with respect to the whole population.

Based on the household net incomes we estimate the distributional and the labour supply effects of the analysed tax reforms. For the econometric estimation of labour supply elasticities, we apply a structural discrete choice household labour supply model following Van Soest (1995). In the standard continuous model (see Hausman (1985)), labour supply responds along the intensive margin: an infinitesimal change of the marginal tax rate changes the working hours only a little, whereas participation responses cannot be satisfactorily analysed within this framework (Blundell and MaCurdy (1999)). Discrete choice labour supply models allow to analyse both the extensive (participation) and the intensive (hours worked) labour supply decision within the same modelling framework (Blundell and MaCurdy (1999), Van Soest and Das (2001), and Van Soest et al. (2002)). The intensive decision depends on the effective marginal tax rate, whereas the extensive participation decision depends on the tax wedge between gross (pre-tax) labour costs and the after-tax net income of workers (see Kleven and Kreiner (2006)). The continuous model "appears not to capture the data, in the sense that the number of part-time jobs is strongly overpredicted" (Van Soest (1995)). There seems to be a lack of part-time jobs because of fixed costs of hiring workers or increasing returns to scale of the worker's production. Furthermore, because of fixed costs of working (Cogan (1981)), individuals are not willing to work below a minimum number of hours. In addition, there are working time regulations 
that limit the number of possible working hours to a discrete set. Therefore, a discrete choice between distinct categories of working time seems to be more realistic than a continuum of infinitesimal choices. Using a discrete choice labour supply model has also the advantage to model nonlinear budget constraints as a result of, for example, nonlinear taxes, joint filing and unemployment benefits (see MaCurdy et al. (1990), Van Soest (1995) or Blundell and MaCurdy (1999)) and to incorporate a richer stochastic specification in terms of unobserved wage rates of nonworkers and random preferences.

Finally, FiFoSiM contains a CGE module for the estimation of growth and employment effects, which is linked to the tax benefit module. This interaction allows for a better calibration of the model parameters and a more accurate estimation of the various effects of reform proposals. FiFoSiM has so far used either the top-down or the bottom-up approach to combine the microsimulation and the CGE module. In the bottom-up linkage the representative household (income, labour supply, tax payments) in the CGE module is calibrated based on the simulation results of the microsimulation modules. For the top-down linkage changes of the wage or price level are computed in the CGE model and used in the microsimulation modules for the calculation of net incomes and the labour supply estimation. The top-down bottom-up approach used for this analysis is so far only executed manually and not automatically. ${ }^{27}$

\section{Cash flow flat tax proposal}

The proposal of Mitschke (2004) in its original version combines an almost flat rate tax (two brackets with different marginal rates) on earned income with a S-base cash flow tax, i.e. income which is invested in firms is tax exempt. ${ }^{28}$ Therefore, the neutrality of the savings and investment decision is achieved through this S-base cash flow tax. In effect, this reform proposal is a switch from an income based tax system to consumption taxation (concept of deferred taxation). ${ }^{29}$ In principle, this proposal is close to the "Flat Tax" idea of Hall and Rabushka (1985) which combines a R-base cash flow taxation on corporate income with the same single marginal tax rate on labour income. ${ }^{30}$ Essentially, the HR flat tax is a consumption-type, origin-based VAT

\footnotetext{
${ }^{27}$ So far, the MSM module is written in Stata and the CGE module in GAMS. The interfacing and the information exchange has to be executed manually. We are currently implementing a routine to automatically execute the GAMS program from Stata, read in the modified CGE parameters, resolve the MSM model, write the modified MSM in GAMS format, execute the CGE model and so on until convergence is achieved. However, it appears to be useful to manually check the results to be able to quickly identify possible problems.

${ }^{28}$ See Fuest et al. (2005a) and Fuest et al. (2007a) for a detailed description and analysis of the Mitschke proposal.

${ }^{29}$ See also Auerbach (2006).

${ }^{30}$ See King (1987) and OECD (2007) for a review of the different concepts of corporate cash flow taxes.
} 
with a tax credit for labour income. ${ }^{31}$

In contrast to Mitschke (2004), who chooses a progressive tax schedule with two brackets, we model a single marginal tax rate of $25 \%^{32}$ for all types of income with a basic allowance of 7,500 Euros in this paper. The Mitschke proposal further distinguishes between an introductory phase (personal income tax reform) and a final phase (personal income tax and cash flow corporate tax). In the first phase, only the personal income tax system is changed to a system with a single marginal rate on all sources of income (including capital and business income). In the final phase, the modified personal income tax is combined with a cash flow corporate income tax with the same marginal rate. ${ }^{33}$ Furthermore, an imputed rent on owner occupied housing is also part of the tax base in this phase. For both phases the long-term revenue, employment and growth effects are simulated as well as the distributional effects.

\section{Analysis}

In the first step, the fiscal effects are analysed in the tax benefit module without taking into account the behavioural reactions of the economic agents (first round effects). In the second step, we allow for behavioural reactions by estimating the labour supply responses (second round effects). We find considerable differences in the labour supply reactions between couples and singles as well as between men and women. While married men increase their labour supply the strongest, single women even slightly decrease their labour supply. In the third step, the labour demand and wage changes (third round effects) are computed in the CGE module. In the fourth step, the micro data information is used to calibrate the representative household in the CGE module for the computation of the overall employment and growth effects (general equilibrium). We link the tax benefit module to the CGE model by using the microsimulation results to calibrate the representative household in terms of income, labour supply and tax payments. As we use static MSM and CGE models, the behavioural adjustments are computed in the long-run, whereas the first round effects represent the immediate short-run effects the "day after" the reform. The main results are summarised in table 2.

The Mitschke proposal includes measures to broaden the tax base, therefore it is not clear ex ante if the tax revenue will be higher or lower than in the status quo. ${ }^{34}$ The shift from the

\footnotetext{
${ }^{31}$ See Keen et al. (2007). The tax base is sales minus purchases with capital goods being excluded (R-base). Further on, this origin-based VAT is a tax on domestic production that taxes exports but not imports (in contrast to the destination-based form of VAT).

${ }^{32}$ The marginal rate of $25 \%$ is computed from micro data as an average tax rate of taxpayers under the Mitschke proposal. The basic allowance is chosen such that the Mitschke flat tax yields the same revenue as the Mitschke two bracket schedule.

${ }^{33}$ Note that in contrast to HR, the VAT is not changed in the Mitschke proposal.

${ }^{34}$ It would have been possible to construct the scenarios revenue neutral like in the previous sections. However,
} 


\begin{tabular}{lll|ll} 
Model & Round & Effect & PIT & PIT + CIT \\
\hline \hline MSM & 1 & Tax revenue & -2 billion $€$ & -13 billion $€$ \\
& 2 & Labour supply & $+103,000$ & $+251,000$ \\
\hline CGE & 3 & Labour demand & $+370,000$ & $+540,000$ \\
\hline Link & 4 & Tax revenue after adj. & +3 billion $€$ & -6 billion $€$ \\
& 4 & Employment & $+337,000$ & $+471,000$ \\
& 4 & $\Delta$ GDP & $+1.1 \%$ & $+1.7 \%$
\end{tabular}

Table 2: Summary of results for the HR type flat tax reform

current German tax regime to the Mitschke proposal would result in revenue losses amounting to $€ 2$ billion in the introductory phase (i.e. flat personal income tax, PIT) respectively $€$ 13 billion in the final phase (i.e. flat personal income tax and cash flow flat corporate income tax, CIT) without taking the behavioural responses into account (first round effects). These short-run effects indicate that the (not revenue neutral) flat tax reform scenario reduces the average tax burden on labour. As a consequence of this lower tax wedge, the net wage is likely to increase and the gross wage is likely to decrease. These effects imply increasing labour supply as well as increasing labour demand due to reduced user costs of labour. These effects will be simulated in the next step. As mentioned before, the behavioural responses are expectations for the long-run (partial or general) equilibrium as both models are static, i.e. not taking the transition path into account.

Labour supply would increase by 103,000 [251,000] fulltime equivalents. By including those second round effects, revenue increases and revenue losses are lowered. So far, these results are only based on the MSM. This information is now used to calibrate the representative household of the CGE model to derive the third round effects: Labour demand would increase by 370,000 $[540,000]$ due to reduced costs of capital and labour. ${ }^{35}$ Taking these effects on wages and prices into account allows us to resolve both models until they converge. This leads to the following results: employment would grow by 337,000 full-time jobs, and GDP would increase by $1.1 \%$ in the introductory phase. The overall employment effects are larger than the labour supply reactions because of reduced costs of labour and capital resulting in increasing labour and investment demand. ${ }^{36}$ This result indicates the importance of taking general equilibrium effects into account. For the final phase, we calculate a total of 471,000 new full-time jobs and a $1.7 \%$ increase in GDP. These results show that a cash flow flat tax leads to further efficiency

the HR idea as well as the Mitschke proposal are not designed to be revenue neutral. Furthermore, allowing for a first round loss in revenue might trigger stronger efficiency effects than a revenue neutral scenario. Therefore, the analysis in this section allows for a loss (or increase) in tax revenue.

${ }^{35}$ This result implies that the incidence of the tax reform is split between employees and employers.

${ }^{36}$ These results are in line with results from Aaberge et al. (2007) for Norway. They also derive for a flat personal income tax scenario that the general equilibrium effects are larger than the pure labour supply reactions. 
gains due to more investment and labour demand as a consequence of reduced tax distortions in the corporate sector.

Can such a reform overcome the fundamental equity efficiency trade-off? The distributional effects before any (short run) and after the complete (long run) adjustment process are presented in Table 3.

\begin{tabular}{l|rr|rr} 
& \multicolumn{2}{|c|}{ Short-run } & \multicolumn{2}{c}{ Long-run } \\
Decile & PIT & PIT+CIT & PIT & PIT+CIT \\
\hline \hline 1 & 0,67 & 0,86 & 77,93 & 78,18 \\
2 & 0,00 & $-0,28$ & 11,68 & 11,41 \\
3 & $-0,29$ & $-1,71$ & 6,33 & 4,70 \\
4 & $-0,66$ & $-2,54$ & 3,30 & 1,47 \\
5 & $-1,27$ & $-2,64$ & 0,73 & $-0,54$ \\
6 & $-1,89$ & $-2,53$ & $-0,54$ & $-1,00$ \\
7 & $-2,31$ & $-1,75$ & $-2,03$ & $-1,09$ \\
8 & $-2,56$ & $-0,31$ & $-3,35$ & $-0,68$ \\
9 & $-2,27$ & 0,73 & $-3,24$ & 0,95 \\
10 & 2,11 & 5,92 & 1,69 & 6,47 \\
\hline Gini & 1,16 & 4,48 & $-2,75$ & 1,28
\end{tabular}

Table 3: Changes in household disposable income (in percent)

Without taking any behavioural responses or adjustments into account (short-term first round effects) inequality increases in both phases. The main reason is the relief for the top of the distribution. The small gains at the lower end cannot compensate the higher burden in the middle income range and therefore inequality increases. These effects change, however, after the economy has fully equilibrated. The introduction of the personal income flat tax reduces inequality because of the strong behavioural responses at the bottom of the distribution. When combining the personal income flat tax with the corporate cash-flow tax, however, inequality still increases but less than without behavioural adjustment. This is due to the fact that especially the high income households have corporate or business income.

To sum up, taking the general equilibrium effects into account has important implications for the evaluation of tax reforms. The analysis shows that a personal income flat tax can indeed overcome the fundamental equity efficiency trade-off in the long-run while simultaneously increasing the tax revenue. However, this result does not hold for a cash flow flat tax combining a personal income flat tax with a corporate cash flow flat tax, even when allowing for an ex-post loss in revenue. 


\section{Conclusion}

The success of the flat rate income tax in Eastern Europe suggests that this concept could also be a model for countries of Western Europe. A linked MSM-CGE model provides a powerful tool for the ex-ante evaluation of hypothetical tax benefit reform proposals and is the most appropriate method for a comprehensive analysis of the distributional, employment and growth effects of (flat) tax reforms. When interpreting these results and especially the efficiency effects, it has to be taken into account that we have limited our analysis to static models. Therefore, the effects from our analysis only account for the new long-run equilibrium neglecting the transition path. ${ }^{37}$ However, regarding the political feasibility of a flat tax reform, the short-term effects are most likely to be decisive. ${ }^{38}$

In this paper, we analysed the introduction of a comprehensive cash flow flat tax in the tradition of Hall and Rabushka (1985). Using the linked MSM-CGE module, we were able to account for the long-run general equilibrium effects. The analysis showed that the overall employment effects are larger than the labour supply reactions because of reduced costs of labour and capital resulting in increasing labour and investment demand. Therefore, it is important to take these general equilibrium effects into account. In doing so, the analysis shows that a personal income flat tax can overcome the familiar equity efficiency trade-off, but only in the long-run. The adverse immediate distributional effects still dominate in the short-run. However, combining this flat tax with a cash flow flat tax on business income with the same marginal rate still increases inequality due to the large gains at the top of the distribution at the expense of the middle class. This is important from a political economy perspective. A strong and politically powerful middle class is a typical characteristic of most Western European countries. This suggests that it will be hard for flat tax reforms to spill over to these grown-up democracies. Since our analysis focuses on Germany, the question arises whether the main findings are likely to apply to other countries as well. Therefore, more (and especially comparative) country studies are required to complete the picture. However, a multi-country linked MSM-CGE model has not been developed yet.

An aspect that is neglected in our analysis is the impact of tax reforms on training and human capital accumulation. The results in Jacobs et al. (2007) suggest that flat tax reforms may increase investment in skill formation and thus change the composition of the labour

\footnotetext{
${ }^{37}$ Flat taxes are also supposed to have positive dynamic efficiency and growth effects (see e.g. Stokey and Rebelo (1995) or Cassou and Lansing (2004)).

${ }^{38}$ People tend to judge future gains and losses asymmetrically (see e.g. the "prospect theory" by Kahneman and Tversky (1979)). Starting from a reference point (status quo) and given the same variation in absolute values, there is a bigger impact of losses than of gains (loss aversion). Furthermore, people prefer the status quo over uncertain outcomes in the future ("status-quo-bias", see Kahneman et al. (1991)). Therefore, short-term losses in comparison to the status quo can have a much stronger impact than (possible) future gains. Hence, the short term effects presented here could be decisive.
} 
force in the long term. But the question arises whether the income tax is the best instrument to achieve this. Furthermore, our analysis abstracts from effects of the flat tax reform on compliance. Flat rate tax systems are widely expected to improve taxpayer compliance. The 2001 tax reform in Russia is widely thought to be an example for this effect. Indeed, tax compliance and revenue apparently improved by about one third after the 2001 tax reform (Ivanova et al. (2005)). However, it is not clear whether this can be attributed solely to the flat tax or to improved law enforcement and tax administration which was also part of the 2001 reform (see also Gaddy and Gale (2005) and Gorodnichenko et al. (2007)). Moreover, the case of Russia differs from Germany insofar as the latter has a long tradition of income taxation in a market economy and a well established tax administration to ensure tax compliance. In addition, since we do not change social insurance contributions, the marginal tax rate on labour still remains high. This suggests that positive effects of a flat tax reform on compliance are probably less important in Germany than in the transition countries of Eastern Europe.

Furthermore, the question arises whether the scope of increasing growth and employment through personal income tax reforms is sufficiently large. The user costs of labour and capital, which play an important role in determining the demand for labour and investment, are rather determined by social security contributions and corporate taxes than by the personal income tax. Including the CIT in the analysis does indeed lead to larger efficiency effects, but at the expense of increasing inequality. Therefore, the main problem of implementing a flat tax would be to convince a majority of the population that an immediate redistribution in favour of the highest income deciles is acceptable to achieve (uncertain) future efficiency gains. Furthermore, it is uncertain whether a tax system that abolishes a large number of exemptions and tax reliefs is politically sustainable. The temptation for politicians to serve special interest groups with special deductions will not easily disappear. Moreover, from a political economy perspective, a broad tax base allows the government to increase revenue with small increases in tax rates. Therefore, narrow tax bases might protect the taxpayers from excess taxation by the government. ${ }^{39}$

\section{References}

Aaberge, R., Colombino, U., Holmøy, E., Strøm, B. and Wennemo, T. (2007). Population Ageing and Fiscal Sustainability: Integrating Detailed Labour Supply Models with CGE Models, in A. Harding and A. Gupta (eds), Modelling Our Future: Social Security and Taxation, Vol. I, Elsevier, Amsterdam, pp. 259-290.

\footnotetext{
${ }^{39}$ Cf. Brennan and Buchanan (1980).
} 
Aaberge, R., Colombino, U. and Strøm, S. (2000). Labor Supply Responses and Welfare Effects from Replacing Current Tax Rules by a Flat Tax: Empirical Evidence from Italy, Norway and Sweden, Journal of Population Economics 13: 595-621.

Altig, D., Auerbach, A., Kotlikoff, L., Smetters, K. and Walliser, J. (2001). Simulating fundamental tax reform in the U. S., American Economic Review 91(3): 574-595.

Anderson, J. M. (1990). Micro-Macro Linkages in Economic Models, in G. H. Lewis and R. C. Michel (eds), Microsimulation Techniques for Tax and Transfer Analysis, Urban Institute Press.

Arntz, M., Boeters, S. and Gürtzgen, N. (2006). Alternative Approaches to Discrete Working Time Choice in an AGE Framework, Economic Modelling 23: 1008-1032.

Arntz, M., Boeters, S., Gürtzgen, N. and Schubert, S. (2006). Analysing Welfare Reform in a Microsimulation-AGE Model: The Value of Disaggregation, ZEW Discussion Paper No. 06-076.

Auerbach, A. J. (2006). The Choice Between Income and Consumption Taxes: A Primer, NBER Working Paper No. 12307.

Auerbach, A. and Kotlikoff, L. (1987). Dynamic Fiscal Policy, Cambridge University Press, Cambridge.

Auerbach, A., Kotlikoff, L. and Skinner, J. (1983). The Efficiency Gains from Dynamic Tax Reform, International Economic Review 24: 97 - 130.

Ballard, C., Fullerton, D., Shoven, J. and Whalley, J. (1985). A General Equilibrium Model for Tax Policy Evaluation, University of Chicago Press, Chicago.

Bergman, L. (2005). CGE Modeling of Environmental Policy and Resource Management, in K. G. Mäler and J. R. Vincent (eds), Handbook of Environmental Economics, NorthHolland, Amsterdam, chapter 24, pp. 1273-1306.

Bergs, C. and Peichl, A. (2008). Numerische Gleichgewichtsmodelle zur Analyse von Politikreformen, Zeitschrift für Wirtschaftspolitik 57 (1): 1-26.

Betson, D. (1990). How Reliable are Conclusions Derived from Microsimulation Models?, in J. Brunner and H.-G. Petersen (eds), Simulation Models in Tax and Transfer Policy: Proceedings of an International Symposium, Campus Verlag, Frankfurt am Main, pp. 423446. 
Blanchard, O. (1985). Debt, Deficits, and Finite Horizons, Journal of Political Economy 93(2): 223-247.

Blundell, R. and MaCurdy, T. (1999). Labor Supply: A Review of Alternative Approaches, in O. Ashenfelter and D. Card (eds), Handbook of Labor Economics, Vol. 3A, Elsevier, Amsterdam, pp. 1559-1695.

Boeters, S., Böhringer, C., Büttner, T. and Kraus, M. (2006). Economic Effects of VAT Reform in Germany, ZEW Discussion Paper No. 06-030.

Boeters, S., Feil, M. and Gürtzgen, N. (2005). Discrete Working Time Choice in an Applied General Equilibrium Model, Computational Economics 26: 183-211.

Boeters, S., Gürtzgen, N. and Schnabel, R. (2006). Reforming Social Welfare in Germany - An Applied General Equilibrium Analysis, German Economic Review 7: 363-388.

Böhringer, C., Boeters, S. and Feil, M. (2005). Taxation and Unemployment: An Applied General Equilibrium Approach, Economic Modelling 22: 81-108.

Böhringer, C. and Rutherford, T. (2006). Combining Top-Down and Bottom-up in Energy Policy Analysis: A Decomposition Approach, ZEW Discussion Paper No. 06-007.

Bourguignon, F., Robilliard, A.-S. and Robinson, S. (2003). Representative versus Real Households in the Macro-Economic Modelling of Inequality, DIAL Document de Travail DT/2003-10.

Bourguignon, F. and Spadaro, A. (2006). Microsimulation as a tool for evaluating redistribution policies, Journal of Economic Inequality 4(1): 77-106.

Bovenberg, L. (2003). Tax Policy and Labor Market Performance, CESifo Working Paper No. 1035.

Brennan, G. and Buchanan, J. (1980). The Power to Tax: Analytical Foundations of a Fiscal Constitution, Cambridge University Press, New York.

Browning, E. and Browning, J. (1985). Why Not a True Flat Rate Tax, Cato Journal 5: 127143.

Cajner, T., Grobovsek, J. and Kozamernik, D. (2006). Welfare and Efficiency Effects of Alternative Tax Reforms in Slovenia, IB Revija (IB Review) XXXX (1-2): 125-136. 
Caminada, K. and Goudswaard, K. (2001). Does a Flat Rate Individual Income Tax Reduce Tax Progressivity? A Simulation for the Netherlands, Public Finance and Management 1 (4): 471-499.

Cassou, S. P. and Lansing, K. J. (2004). Growth Effects of Shifting from a Graduated-rate Tax System to a Flat Tax, Economic Inquiry 42(2): 194-213.

Cogan, J. (1981). Fixed costs and labor supply, Econometrica 49: 945-963.

Cogneau, D. and Robilliard, A.-S. (2000). Growth, Distribution and Poverty in Madagascar: Learning from a Microsimulation Model in a General Equilibrium Framework, International Food Policy Research Institute TMD Discussion Paper 61.

Conrad, K. (1991). Intertemporal General Equilibrium Modelling of German Tax Reform Proposals, Finanzarchiv 48 (2): 194-221.

Cororaton, C. B., Cockburn, J. and Corong, E. (2005). Doha Scenarios, Trade Reforms, and Poverty in the Philippines: A Computable General Equilibrium Analysis, World Bank Policy Research Working Paper 3738.

Creedy, J., Duncan, A., Harris, M. and Scutella, R. (2002). Microsimulation Modelling of Taxation and the Labour Market: the Melbourne Institute Tax and Transfer Simulator, Edward Elgar Publishing, Cheltenham.

Davies, J. (2004). Microsimulation, CGE and Macro Modelling for Transition and Developing Economies, Mimeo, University of Western Ontario.

Díaz Giménez, J. and Pijoan-Mas, J. (2006). Flat Tax Reforms in the US: A Boon for the Income Poor, CEPR Discussion Paper No. 5812.

Decoster, A. and Orsini, K. (2007). Verdient een vlaktaks zichzelf terug?, Leuvense Economische Standpunten, K.U. Leuven, Centrum voor Economische Studiën.

Dunbar, A. and Pogue, T. (1998). Estimating Flat Tax Incidence and Yield: A Sensitivity Analysis, National Tax Journal 51: 303-324.

Fehr, H. and Wiegard, W. (1996). Numerische Gleichgewichtsmodelle: Grundstruktur, Anwendungen und Erkenntnisgehalt, Jahrbuch 13: Experimente in der Ökonomie, Ökonomie und Gesellschaft, Frankfurt, pp. 296-339.

Fehr, H. and Wiegard, W. (1998). German Income Tax Reforms: Separating Efficiency from Redistribution, in A. Fossati and J. Hutton (eds), Policy Simulations in the European Union, Routledge, London, pp. 235-263. 
Fuest, C., Peichl, A. and Schaefer, T. (2005a). Aufkommens-, Beschäftigungs- und Wachstumswirkungen einer Steuerreform nach dem Vorschlag von Mitschke, FiFo-Bericht 05-2005.

Fuest, C., Peichl, A. and Schaefer, T. (2005b). Dokumentation FiFoSiM: Integriertes Steuer-Transfer-Mikrosimulations- und CGE-Modell, Finanzwissenschaftliche Diskussionsbeiträge Nr. 05 - 03.

Fuest, C., Peichl, A. and Schaefer, T. (2007a). Aufkommens-, Beschäftigungs- und Wachstumswirkungen einer Steuerreform nach dem Vorschlag von Mitschke, Nomos, Baden-Baden.

Fuest, C., Peichl, A. and Schaefer, T. (2007b). Is a Flat Tax politically feasible in a grown-up Welfare State?, CPE discussion paper 07-6, University of Cologne.

Gaddy, C. G. and Gale, W. G. (2005). Demythologizing the Russian Flat Tax, Tax Notes International 43: 983-988.

Gale, W. G., Houser, S. and Scholz, J. K. (1996). Distributional Effects of Fundamental Tax Reform, in H. J. Aaron and W. G. Gale (eds), Economic Effects of Fundamental Tax Reform, The Brookings Institution, Washington, D. C., pp. 281-320.

González-Torrabadella, M. and Pijoan-Mas, J. (2006). Flat tax reforms: a general equilibrium evaluation for Spain, Investigaciones Económicas XXX (2): 317-351.

Gorodnichenko, Y., Martinez-Vazquez, J. and Peter, K. S. (2007). Myth and Reality of Flat Tax Reform: Micro Estimates of Tax Evasion Response and Welfare Effects in Russia, IZA Discussion Paper No. 3267.

Graafland, J., de Mooij, R. and Nibbelink, A. (2001). MIMICing Tax Policies and the Labour Market, Elsevier, Amsterdam.

Gupta, A. and Kapur, V. (2000). Microsimulation in Government Policy and Forecasting, North-Holland, Amsterdam.

Haan, P. and Steiner, V. (2005). Distributional Effects of the German Tax Reform 2000 - A Behavioral Microsimulation Analysis, Schmollers Jahrbuch 125 (1): 39-49.

Hall, R. E. and Rabushka, A. (1985). The Flat Tax, Hoover Institution Press, Stanford.

Harding, A. (1996). Microsimulation and public policy, North-Holland, Elsevier, Amsterdam.

Harris, R. (1984). Applied General Equilibrium Analysis of Small Open Economies with Scale Economies and Imperfect Competition, American Economic Review 74: 1017-1032. 
Hausman, J. (1985). Taxes and Labor Supply, in A. Auerbach and M. Feldstein (eds), Handbook of Public Economics, North-Holland, Amsterdam, pp. 213-263.

Heckman, J. (1993). What has been learned about labor supply in the past twenty years?, American Economic Review Papers and Proceedings 85: 116-121.

Heer, B. and Trede, M. (2003). Efficiency and distribution effects of a revenue-neutral income tax reform, Journal of Macroeconomics 25: 87-107.

Ho, M. and Stiroh, K. (1998). Revenue, Progressivity and the Flat Tax, Contemporary Economic Policy XVI: 85-97.

Hérault, N. (2007). Trade Liberalisation, Poverty and Inequality in South Africa: A CGEMicrosimulation analysis, Economic Record 83 (262): 317-328.

Hutton, J. and Ruocco, A. (1999). Tax Reform and Employment in Europe, International Tax and Public Finance 6: 263-287.

Immervoll, H., Kleven, H., Kreiner, C. and Saez, E. (2007). Welfare Reform in European Countries: A Micro-Simulation Analysis, The Economic Journal 117 (516): 1-44.

Ivanova, A., Keen, M. and Klemm, A. (2005). Russia's 'flat tax', Economic Policy July: 397444.

Jacobs, B., de Mooij, R. A. and Folmer, K. (2007). Analyzing a flat income tax in the Netherlands, Tinbergen Institute Discussion Paper 2007-029/3.

Johansen, L. (1960). A Multi-sectoral Study of Economic Growth, North-Holland, Amsterdam.

Kahneman, D., Knetsch, J. L. and Thaler, R. H. (1991). Anomalies: The endowment effect, loss aversion, and status quo bias, Journal of Economic Perspectives 5: 193-206.

Kahneman, D. and Tversky, A. (1979). Prospect theory: An analysis of decision under risk, Econometrica 47: 263-291.

Keen, M., Kim, Y. and Varsano, R. (2007). The 'flat tax(es)': Principles and experience, International Tax and Public Finance forthcoming.

Kehoe, P. and Kehoe, T. (1994). A Primer on Static Applied General Equilibrium Models, Federal Reserve Bank of Minneapolis Quaterly Review 18(1).

Kehoe, T. (1998). Social Accounting Matrices and Applied General Equilibrium Models, Applied Economics and Public Policy pp. 59-87. 
Kehoe, T. and Prescott, E. (1995). Introduction to the Symposium: The Discipline of Applied General Equilibrium, Economic Theory 6: 1-11.

Keuschnigg, C. and Dietz, M. (2003). Unternehmenssteuerreform II - quantitative Auswirkungen auf Wachstum und Verteilung, Paul Haupt, Bern.

King, M. (1987). The Cash Flow Corporate Income Tax, in M. Feldstein (ed.), The Effects of Taxation on Capital Accumulation, University of Chicago Press, Chicago.

Kleven, H. J. and Kreiner, C. (2006). The Marginal Cost of Public Funds in OECD Countries: Hours of Work versus Labor Force Participation, Journal of Public Economics 90: 19551973.

Lau, L. (1984). Comments on Mansur and Whalley (1984), in H. Scarf and J. B. Shoven (eds), Applied General Equilibrium Analysis, Cambridge University Press, New York, pp. 127137.

MaCurdy, T., Green, D. and Paarsch, H. (1990). Assessing Empirical Approaches for Analyzing Taxes and Labor Supply, Journal of Human Resources 25(3): 415-490.

Mansur, A. and Whalley, J. (1984). Numerical Specification of Applied General Equilibrium Models: Estimation, Calibration and Data, in H. Scarf and J. B. Shoven (eds), Applied General Equilibrium Analysis, Cambridge University Press, New York, pp. 69-127.

Merz, J., Stolze, H. and Zwick, M. (2002). Professions, entrepreneurs, employees and the new German tax (cut) reform 2000. A MICSIM microsimulation analysis of distributional impacts, FFB-Diskussionspapier Nr. 35, Universität Lüneburg.

Merz, J. and Zwick, M. (2002). Verteilungswirkungen der Steuerreform 2000/2005 im Vergleich zum Karlsruher Entwurf. Auswirkungen auf die Einkommensverteilung bei Selbständigen, Wirtschaft und Statistik 8: 729-740.

Mitschke, J. (2004). Erneuerung des deutschen Einkommensteuerrechts: Gesetzestextentwurf und Begründung, Verlag Otto Schmidt, Köln.

Nielsen, S. B., Frederiksen, N. K. and Lassen, D. D. (1999). Would the flat tax fall flat in Denmark?, in T. M. Andersen, S. E. H. Jensen and O. Risager (eds), Macroeconomic Perspectives on the Danish Economy, MacMillan, pp. 106-133.

OECD (2007). Fundamental Reform of Corporate Income Tax, OECD Tax Policy Studies 16. 
O'Hare, J. and Gupta, A. (2000). Practical Aspects of Microsimulation Modelling, in A. Gupta and V. Kapur (eds), Microsimulation in Government Policy and Forecasting, NorthHolland, Amsterdam, pp. 563-640.

Orcutt, G. (1957). A new type of socio-economic system, Review of Economics and Statistics 58: $773-797$.

Orcutt, G. (1967). Microeconomic Analysis for Prediction of National Accounts, in H. Wold, G. H. Orcutt, E. A. Robinson, D. Suits and P. de Wolff (eds), Forecasting on a Scientific Basis - Proceedings of an International Summer Institute, Gulbenkian Foundation, Lisbon.

Orcutt, G., Greenberg, M., Korbel, J. and Rivlin, A. (1961). Microanalyis of Socioeconomic Systems: A Simulation Study, Harper and Row, New York.

Paulus, A. and Peichl, A. (2008). Effects of flat tax reforms in Western Europe on equity and efficiency, EUROMOD Working Paper No. EM2/08, University of Essex.

Peichl, A. (2005). Die Evaluation von Steuerreformen durch Simulationsmodelle, Finanzwissenschaftliche Diskussionsbeiträge Nr. 05-01.

Peichl, A. and Schaefer, T. (2006). Documentation FiFoSiM: Integrated Tax Benefit Microsimulation and CGE Model, Finanzwissenschaftliche Diskussionsbeiträge Nr. 06 - 10, Universität zu Köln.

Pyatt, G. and Round, J. (1985). Social Accounting Matrices. A Basis for Planning, The World Bank, Washington D.C.

Radulescu, D. and Stimmelmayr, M. (2004). Implementing a Dual Income Tax in Germany: Effects on Investment and Welfare, Mimeo, Universität München.

Ramsey, F. (1928). A Mathematical Theory of Saving, Economic Journal 543-559: 28.

Rausch, S. and Rutherford, T. F. (2007). Computation of Equilibria in OLG Models With Many Heterogeneous Households, Ruhr Economic Paper No. 15.

Rutherford, T., Tarr, D. and Shepotylo, O. (2005). Poverty Effects of Russia's WTO Accession: Modelling 'Real' Households and Endogenous Productivity Effects, World Bank Policy Research Working Paper 3473.

Savard, L. (2003). Poverty and Income Distribution in a CGE-Household Micro- Simulation Model: Top-Down/Bottom Up Approach, CIRPÉE Centre interuniversitaire sur le risque, les politiques économiques et l'emploi. Working Paper 03-43. 
Shoven, J. and Whalley, J. (1984). Applied General Equilibrium Models of Taxation and International Trade: An Introduction and Survey, Journal of Economic Literature 22: 10071051.

Shoven, J. and Whalley, J. (1992). Applying General Equilibrium, Cambridge University Press, Cambridge.

Sørensen, P. (2002). The German Business Tax Reform of 2000 - A General Equilibrium Analysis, German Economic Review 3: 347-378.

Steiner, V. and Wrohlich, K. (2004). Household Taxation, Income Splitting and Labor Supply Incentives - A Microsimulation Study for Germany, CESifo Economic Studies 50(3): 541568.

Stokey, N. L. and Rebelo, S. (1995). Growth Effects of Flat-Rate Taxes, Journal of Political Economy 103(3): 519-550.

Van Soest, A. (1995). Structural Models of Family Labor Supply: A Discrete Choice Approach, Journal of Human Resources 30: 63-88.

Van Soest, A. and Das, M. (2001). Family Labor Supply and Proposed Tax Reforms in the Netherlands, De Economist 149(2): 191-218.

Van Soest, A., Das, M. and Gong, X. (2002). A Structural Labour Supply Model with flexible Preferences, Journal of Econometrics 107: 345 - 374.

Ventura, G. (1999). Flat Tax Reform: A Quantitative Exploration, Journal of Economic Dynamics and Control 23: 1425-1458.

Verboven, F. (1996). The nested logit model and representative consumer theory, Economic Letters 50 (1): 57-63.

Wagenhals, G. (2001). Incentive and Redistribution Effects of the German Tax Reform 2000, Finanzarchiv 57: 316-332.

Wagenhals, G. (2004). Tax-benefit microsimulation models for Germany: A Survey, IAWReport / Institut fuer Angewandte Wirtschaftsforschung (Tübingen) 32(1): 55-74. 